\title{
Solution Treatment on Mechanical Properties and Microstructures of Al- Li-Cu Alloy
}

Yu Cheng, Yin Deng Feng*and Yu Xin Xiang

School of Materials Science and Engineering, Central South University, Changsha 410083, China

\begin{abstract}
The mechanical properties and microstructures of $\mathrm{Al}-\mathrm{Li}-\mathrm{Cu}-\mathrm{Mg}-\mathrm{Ag}$ alloy after different solution treatments were investigated by means of Optical Microscopy (OM), tensile test, hardness and electrical conductivity tests, Differential Scanning Calorimetry (DSC), Energy Dispersive X-ray (EDX), Scanning Electron Microscopy (SEM) and Transmission Electron Microscopy (TEM). Results show that the tensile strength and hardness increase firstly and then decrease with elevating solution temperature when the holding time is kept for $30 \mathrm{~min}$, and the maximum strength and hardness are reached when temperature is $520^{\circ} \mathrm{C}$. The mechanical properties of alloy also display similar trend, which increase firstly and then decrease with increasing solution time when alloy is treated at $520^{\circ} \mathrm{C}$. The tensile strength, hardness and elongation of the alloy solution treated at $520^{\circ} \mathrm{C} / 30 \mathrm{~min}$ are $566 \mathrm{Mpa}(\sigma \mathrm{b}), 512$ $\mathrm{Mpa}(\sigma 0.2), 148 \mathrm{HB}$ and $8.23 \%(\delta)$, respectively. TEM shows that an amount of $\mathrm{T} 1$ ( $\mathrm{Al}_{2} \mathrm{CuLi}$ ) phases are finely and dispersedly distributed in Al substrates, which can be an explanation of a mixed fracture mode of transgranular and intergranular delamination cracks observed by SEM.
\end{abstract}

Keywords: Al-Li-Cu-Mg-Ag alloy; Solution treatment; Microstructure; Mechanical properties; T1

\section{Introduction}

Commercial aluminium-lithium-copper alloy has high specific modulus, high strength, high stiffness resistance and low density, which makes it interesting for many material scientists [1-2]. Due to its excellent-comprehensive properties, it is used increasingly for aerospace construction and aircraft industry. Since 1980s, many researchers [3] have made a lot of studies on $\mathrm{Al}-\mathrm{Cu}-\mathrm{Li}$ alloy about its physical and mechanical properties at the stage of solution-heat treatment, and they have achieved great progresses.

The mechanical properties and microstructures of $\mathrm{Al}-\mathrm{Li}-\mathrm{Cu}$ alloy are very sensitive to structures of alloy solidification schemes of heat treatments and subsequent deformation conditions [4]. Alloy always gets through different heat treatment processes so as to get the mechanical properties improved. Apparently, solution treatment is thought as one of the first step in the whole heat treatments $[5,6]$. During solution treatment, the alloy is exposed to as high temperature as possible but limited to the lowest melting point. By doing so, the bulk soluble phases' elements including $\mathrm{Cu}, \mathrm{Li}, \mathrm{Mg}$ etc will re-dissolve into the alloy matrix in solution-heat treatment heating so as to get a supersaturated solution solid, which is beneficial to subsequent aging. As a result, the studies on the effects of solution treatments are significant and beneficial to get a promoted mechanical property of AlLi-Cu-Mg-Ag alloy.

Recently, there are many papers about the relationship between principles of heat treatments and microstructures of Al-Li-Cu-Mg-Ag alloy, but these are focused on aging procedures.

\section{Experiments}

The present experimental materials as listed in Table 1 were prepared with pure $\mathrm{Al}$, pure $\mathrm{Li}$, pure $\mathrm{Mg}$ and intermediate alloy $\mathrm{Al}$ $\mathrm{cu}, \mathrm{Al}-\mathrm{Zr}, \mathrm{Al}-\mathrm{Ce}$ (etc), which were melted in a induction graphite crucible under protection of Ar. The ingots were homogenized at $450^{\circ} \mathrm{C} / 160 \mathrm{~h}+500^{\circ} \mathrm{C} / 8 \mathrm{~h}$ in a salt bath furnace and then were hot and cold rolled to $2 \mathrm{~mm}$. The tensile specimens were parallel to the rolling direction. Samples cut from alloy sheet were solution-heat treated at $510^{\circ} \mathrm{C}, 515^{\circ} \mathrm{C}, 520^{\circ} \mathrm{C}$ and $525^{\circ} \mathrm{C}$ for different period of time in a salt bath which is shown in Table 2, and then suffered artificial aging at $160^{\circ} \mathrm{C} / 20 \mathrm{~h}$.

Tensile tests were carried out on a WD-10A tensile machine or mechanical deformation and the effect of solution treatment is paid little attention [7]. In this work, we have studied the effects of solution treatments on microstructures and physical properties of $\mathrm{Al}-\mathrm{Li}-\mathrm{Cu}$ alloy by mechanical tests, SEM and TEM analysis. The appropriate solution treatment parameters are received and the results can provide indispensable information for further study on heat treatment of Al-Li$\mathrm{Cu}-\mathrm{Mg}-\mathrm{Ag}$ alloy at rate of $2 \mathrm{~mm} / \mathrm{min}$, hardness tests were performed on HBE-3000 machine loading at $250 \mathrm{~kg}$ for $30 \mathrm{~s}$, and electrical conductivity tests were done on D60K digital metal measurement. The metallurgical structures of alloy whose specimens were grinded, polished, rewashed and etched with Keller solution were observed at POLYVER-MET optical microscopy. The fracture morphology of

\begin{tabular}{|l|c|c|c|c|c|c|c|}
\hline Alloy element & $\mathrm{Cu}$ & $\mathrm{Li}$ & $\mathrm{Mg}$ & $\mathrm{Ag}$ & $\mathrm{Zr}$ & $\mathrm{Ce}$ & $\mathrm{Al}$ \\
\hline Content/wt.\% & 5.8 & 1.3 & 0.4 & 0.4 & 0.14 & 0.3 & bal \\
\hline
\end{tabular}

Table 1: Chemical compositions of the experimental alloy.

\begin{tabular}{|c|c|c|c|c|}
\hline Solution temperature $/{ }^{\circ} \mathrm{C}$ & 510 & 515 & 520 & 525 \\
\hline \multirow{3}{*}{ Solution time/min } & - & - & 20 & - \\
\cline { 2 - 5 } & 30 & 30 & 30 & 30 \\
\cline { 2 - 5 } & - & - & 40 & - \\
\cline { 2 - 5 } & - & - & 50 & - \\
\hline
\end{tabular}

Table 2: Schedule solution treatment of Al-Li-Cu-Mg-Ag

*Corresponding author: Yin Deng Feng, Associate professor, School of Materials Science and Engineering, Central South University, Changsha 410083, China, E-mail: dfyin@126.com

Received May 30, 2012; Accepted July 24, 2012; Published July 30, 2012

Citation: Cheng Y, Feng YD, Xiang YX (2012) Solution Treatment on Mechanical Properties and Microstructures of Al-Li-Cu Alloy. J Material Sci Eng 1:106. doi:10.4172/2169-0022.1000106

Copyright: ( $) 2012$ Cheng Y, et al. This is an open-access article distributed under the terms of the Creative Commons Attribution License, which permits unrestricted use, distribution, and reproduction in any medium, provided the original author and source are credited. 
tensile tests were conducted at KYKY-1000 SEM and the TEM was finished at TECNAl G220 machine. The composition of the large second particles was measured by Energy Dispersive X-ray (EDX) analyzer. DSC analysis and electrical conductivity tests were carried out on SDT-Q600 differential scanning calorimeter and D60K digital metallic conductivity machine. The specimens for TEM were prepared by the twin-jet electro-polishing using 75\% methanol and 25\% nitric solution at $-30^{\circ} \mathrm{C}$

\section{Results}

\section{Mechanical properties of aged Al-Li-Cu-Mg-Ag alloy with different solution treatments}

Figures 1 and 2 show the mechanical properties of $\mathrm{Al}-\mathrm{Li}-\mathrm{Cu}-\mathrm{Mg}$ alloy studied in this work when solution-heat treatment is performed at different temperature and various times. Figure 1 shows that tensile strength, for instance, ultimate tensile strength $(\sigma \mathrm{b})$, yield tensile strength $(\sigma 0.2)$ tend to increase firstly with elevating solution temperature and time and then decrease; while the elongation $(\delta)$ is opposite, it shows a reduction along with increasing solution temperature and time. Elongation of this alloy is reducing from $9.9 \%$ to $7.24 \%$ along with elevation of the temperature. $\sigma \mathrm{b}$ and $\sigma 0.2$ increase respectively with temperature between $500-520^{\circ} \mathrm{C}$, and then decrease slightly when the temperature preponderates over $520^{\circ} \mathrm{C}$, but the strength still remains at a high level. The maximum values of $\sigma \mathrm{b}$ and $\sigma 0.2$ are $563.4 \mathrm{Mpa}$ and $506.2 \mathrm{Mpa}$ when solution-heat treatment temperature is around $520^{\circ} \mathrm{C}$ and $30 \mathrm{~min}$. Results of Figure 1 demonstrate that tensile properties and ductility are well combined when the $\mathrm{Al}-\mathrm{Li}-\mathrm{Cu}-\mathrm{Mg}$ alloy containing minor $\mathrm{Ag}, \mathrm{Zr}$ and Ce is solution treated at temperature $520^{\circ} \mathrm{C}$ for $30 \mathrm{~min}$. The effect of solution treatment on hardness and electrical conductivity of this alloy is shown in the Figure 2 . We can find that hardness increases rapidly with elevating temperature before $520^{\circ} \mathrm{C}$ and solution heated time until $30 \mathrm{~min}$, which is common with those of tensile properties treated by different solution temperature and time in Figure 2a. The electrical conductivity cannot only reflect the conductivity of materials, but also shows critical relations with conditions of materials' heat treatments. Nevertheless, electrical conductivity of this alloy has a bit difference when treated at various solution times [8-10]. A drop of electrical conductivity occurs before $30 \mathrm{~min}$, but then it keeps neither increasing nor reducing from 30 to $50 \mathrm{~min}$. Many researchers have reported about these changes, but there is no exact evidence on explanation of this planar stage in the Figure $2 \mathrm{~b}$. Therefore, the optimum temperature and time of solution-heat treatment deduced from the results of the experiments are $520^{\circ} \mathrm{C}$ and $30 \mathrm{~min}$, which has significant influences on further artificial aging characteristics.

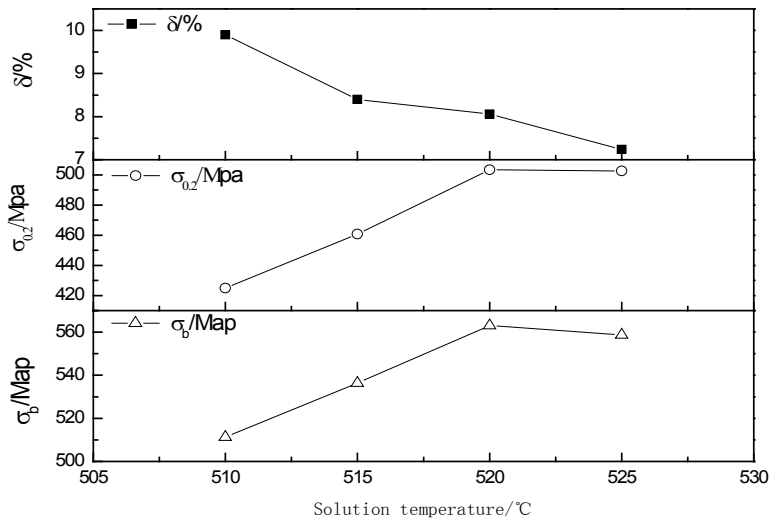

(a)

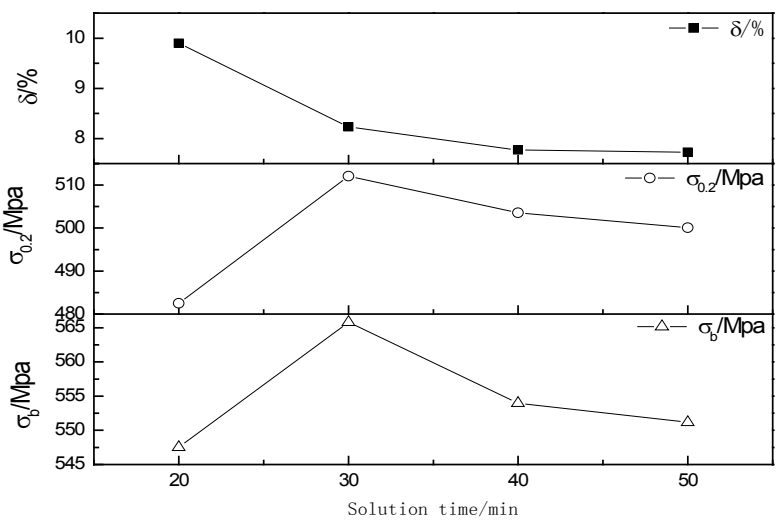

(b)

Figure 1: Tensile properties of aged alloy treated by solution treatments: (a) solution temperature; (b) solution time.

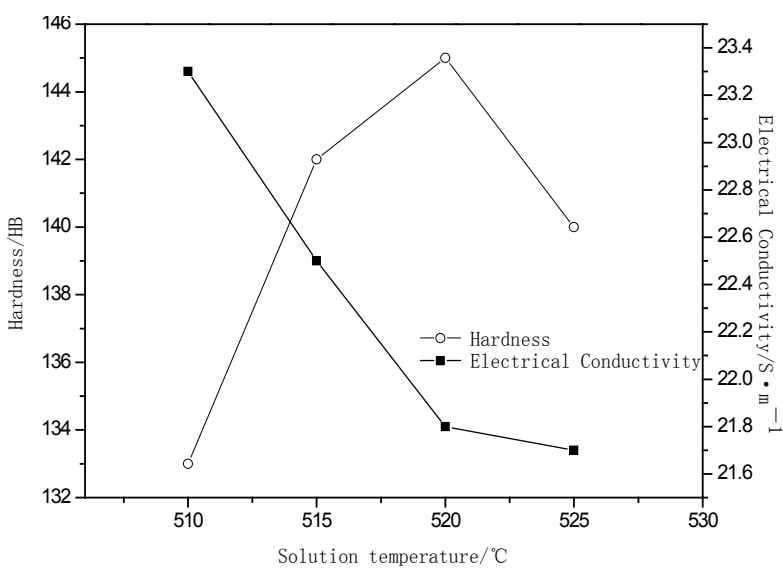

(a)

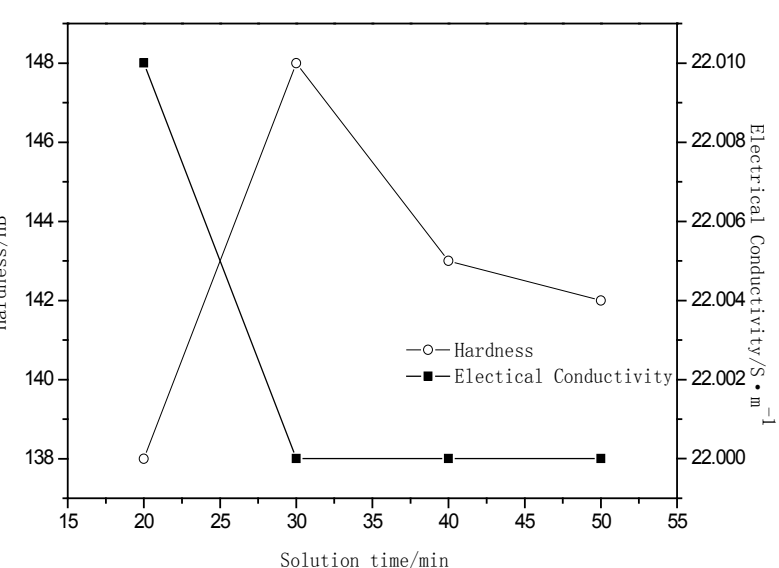

(b)

Figure 2: Hardness and electrical conductivity of aged alloy treated by solution treatments: (a) solution temperature; (b) solution time. 


\section{Effects of solution treatments on microstructures}

EDX and DSC analysis of residual phases: Figure 3 shows microstructures of alloy observed on SEM after solution treatments and DSC curve. Apparently, there are some different sizes of residual phase in matrix of alloy. From the Figure 3a, these insolvable particles have spherical, bulk and rod morphologies. EDX was used to analyze these residual phases, as shown in Figure $3 \mathrm{~b}$ and $3 \mathrm{c}$. Results show that two undissolved particles can be qualitatively studied. The spherical particles pointed at a red arrow are a Fe-rich phase $\left(\mathrm{Al}_{7} \mathrm{Cu}_{2} \mathrm{Fe}\right)$, whose content is very small given in Figure $3 \mathrm{c}$. The Fe-rich phase $\left(\mathrm{Al}_{7} \mathrm{Cu}_{2} \mathrm{Fe}\right)$ is formed during solidification of liquid alloy and hardly dissolves into $\mathrm{Al}$ matrix when heated in homogenization and solution treatments. And the other morphology pointed at a blue arrow is a $\mathrm{Cu}$-rich phase, $\theta^{\prime}\left(\mathrm{Al}_{2} \mathrm{Cu}\right)$, which is the main strengthening phase in Al-Li alloy.

Figure $3 \mathrm{~d}$ shows the DSC curve of alloy. There are four peaks in the curve, which are marked by letters A, B, C and D. Apparently, little changes happen at the temperature between 180 to $490^{\circ} \mathrm{C}$, but endothermic and exothermic reaction occurs around $518-550^{\circ} \mathrm{C}$, for instance, A, B and C. A clear peak of endothermic reaction shows at A dot, $525^{\circ} \mathrm{C}$, which may refer to re-dissolution of atom clusters, second phases and impurities particles which formed during solidification of liquid metal alloy. An alloy is prone to overheat when the temperature exceeds over A dot. A small peak in B on the thermograph curve results from re-precipitation of second meta-stable phase $\delta^{\prime}$ or GuinierPreston (GPB) zones, due to the consequence of heat flow from the DSC instrument. Moreover, $\mathrm{C}$ dot suggests that most particles have disappeared and alloy matrix is under the state of super-saturation. When the temperature surpasses $\mathrm{D}\left(650-600^{\circ} \mathrm{C}\right)$, liquid metal phases will turn up. According to the result of DSC experiment, we can find that the temperature of solution treatment should be low at $525^{\circ} \mathrm{C}$. So we select $520^{\circ} \mathrm{C} / 30 \mathrm{~min}$ for solution treatment, which is consistent with the optimum mechanical properties shown in Figures 1 and 2.

Influence of solution treatment on microstructures: Figure 4 depicts some micrographic metallurgy photos of alloy, where letters Figure $4 \mathrm{a}-4 \mathrm{~d}$ stand for samples solution-treated at temperature from $510-520^{\circ} \mathrm{C}$, and the others, Figure $4 \mathrm{e}$ and $4 \mathrm{f}$ mean that specimens are heated with the solution treatment at the same temperature, optimum values at $520^{\circ} \mathrm{C}$ for $20,30,40,50 \mathrm{~min}$. In Figure $4 \mathrm{a}$, there are many remaining second phases and large particles distributed along the grain boundaries. Size of grains is not homogeneous and dislocations are tangled around subgrain boundaries. With the temperature increasing, solute elements and solvable small phases dissolve into aluminiummatrix and the density of dislocations gets smaller and smaller, but the contents of vacuums increases fastly [11]. Residual unmelted particles mostly accumulate around the grain boundaries and their number is small when solution treatment temperature was $520^{\circ} \mathrm{C}$, which is clearly shown in Figure $4 \mathrm{c}$. However, when the
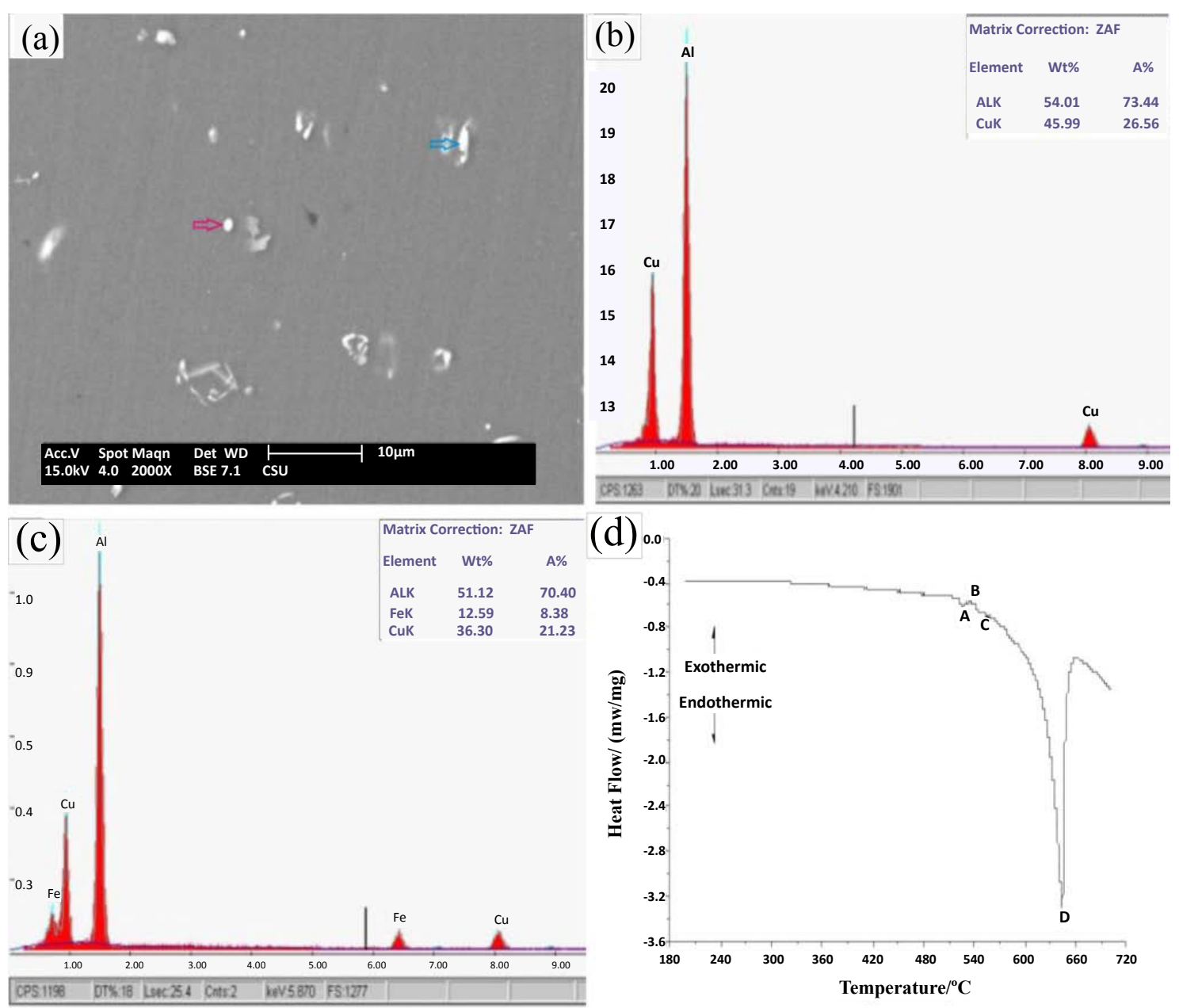

Figure 3: EDX graphs of residual phases and DSC curve. 
temperature goes up to $525^{\circ} \mathrm{C}$, those second phases and alloy elements will begin to re-precipitate and grow along with grain and subgrain boundaries, which is harmful to ductility and toughness of Al-Li alloy, as is depicted in the Figure $4 \mathrm{~d}$. Microscopy figures (Figure $4 \mathrm{e}$ and $4 \mathrm{f}$ ) also witness the similar results shown in Figures $4 \mathrm{a}$ and $4 \mathrm{~d}$. So, the optical microscopy structures of alloy are susceptible to the solution treatment temperature and time, which can be demonstrated by the relatives between microstructures and mechanical properties shown in Figures 1 and 2. Figure 5 displays the SEM tensiled fracture surfaces of aged $\mathrm{Al}-\mathrm{Li}-\mathrm{Cu}-\mathrm{Mg}-\mathrm{Ag}$ alloy treated at various solution treatments. We can find that the format of tensiled fracture is clearly cleavage fracture and delamination cracks, as shown in Figure 5a. There are a little of small dimples with different size and shapes around delaminated structures, which is an indication that part of the failure is the result of ductile fracture. However, with the increasing solution temperature, lamellar structures of delamination get clear and the morphology of failure is transferring from transgranular crack to a combination of transgranular and intergrannlar fracture. In Figure 6b, the lamellar structures and dimples is thinner, smaller and deeper than those shown in Figure $6 \mathrm{a}$ and $6 \mathrm{c}$. But the morphology of fracture tend to be a smooth crystal-sugar shape when the temperature gets up from 520 to $525^{\circ} \mathrm{C}$. The magnification of fracture face of alloy treated at optimum processing, $520^{\circ} \mathrm{C} / 30 \mathrm{~min}$ in Figure $5 \mathrm{~d}$, shows that the thin delaminated structures and dimples make many contributions to the combination between strength and ductility, which can demonstrate the results in mechanical properties tests in Figure 1 and 2.

Figure 6 depicts TEM micrographs of precipitates of aged alloy treated by different solution treatments. Apparently, there are plenty of aging strength precipitates, T1 phase which can be determined from the diffraction mottles in the Figure $6 f$ at the [100] direction, homogeneously precipitated in alloy matrix, and some $\theta$ ' phase also can be detected respectively. From the Figure $6 a$ to $6 c$, when the solution temperature is $510^{\circ} \mathrm{C}$, the number and size of precipitates are small, but distribute dispersedly. With increasing temperature, the density of these main strength phases gets greater and more homogeneously and they come to grow, as shown in Figure $6 \mathrm{~b}$ and $6 \mathrm{c}$. The precipitate free zone around grain boundary in aging alloy solution treated at $520^{\circ} \mathrm{C} / 30 \mathrm{~min}$ is very narrow and little precipitates are observed, which can make significant contribution to the strength of the alloy as displayed in the Figure 6e.

\section{Analysis and Discussion}

As discussed before, an enhanced tensile strength and toughness can be obtained by appropriate solution treatment that trends to make the alloy elements and precipitations redissolve into $\mathrm{Al}$ matrix mostly $[12,13]$, which lead to get fine grains and facilitate further artificial aging hardness. The main parameters of solution treatment are the solution holding time and solution temperature, which have significant effects on mechanical properties. A proper solution temperature is necessary for the heat treatment of $\mathrm{Al}-\mathrm{Li}-\mathrm{Cu}-\mathrm{Mg}-\mathrm{Ag}$ alloy. To some extent, the higher temperature and the more redissolution of elements are, the higher strength of aged alloy after solution treatment gets [14]. It is apparent that the strength mechanisms for $\mathrm{Al}-\mathrm{Li}-\mathrm{Cu}-\mathrm{Mg}$-Ag alloy are major fine grain strengthening and precipitation strengthening when treated at different solution conditions and then treated at the same aging condition. The precipitation strengthening is attributed to the great plenty of solution atoms during solution treatments, which is to the benefit of precipitation in the following aging treatment [15]. With increasing temperature which is below the over burnt temperature of alloy, much more residual phases are redissolved into the $\mathrm{Al}$ matrix, which results in a higher strength of $\mathrm{Al}-\mathrm{Li}-\mathrm{Cu}-\mathrm{Mg}-\mathrm{Ag}$ alloy. And the extent of lattice distortion and probability of electron diffraction will also increase quickly, leading to reduction of mechanical and physical properties. Similarly, the fraction of microstructure recrystallization and grain size increase significantly with the increasing solution temperature, according to Hall-Petch functions relationships [16] leading to decreasing the effects of the fine grain strengthening. The results of tensile and hardness tests are convincing evidences in Figure 1. And electrical conductivity decreases with the elevation of temperature till $520^{\circ} \mathrm{C}$, then keeps at a stable level around at 22.00 , shown in Figure 2, though temperature increases. This means that solubility of the solution atoms is close to supersaturation. Alloy obtains

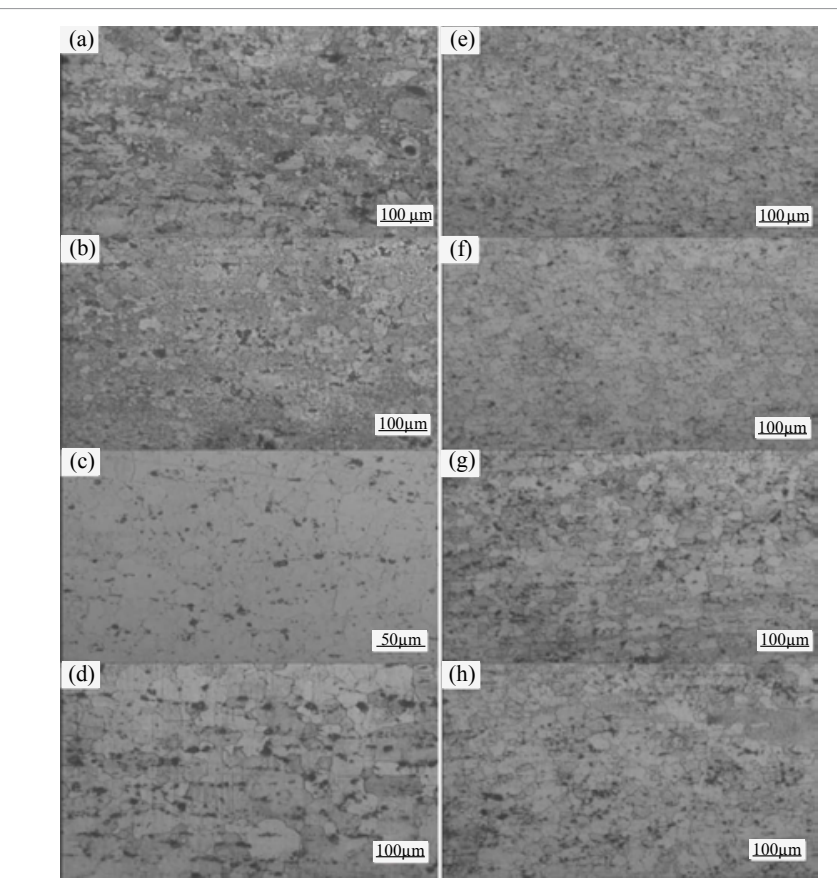

Figure 4: Optical microscopy structures of Al-Li alloy: (a) $510^{\circ} \mathrm{C}$; (b) $515^{\circ} \mathrm{C}$; (c) $520^{\circ} \mathrm{C}$; (d) $525^{\circ} \mathrm{C}$; (e) $520^{\circ} \mathrm{C} / 20 \mathrm{~min}$; (f) $520^{\circ} \mathrm{C} / 30 \mathrm{~min}$; (g) $520^{\circ} \mathrm{C} / 40 \mathrm{~min}$; (h) $520^{\circ} \mathrm{C} / 50 \mathrm{~min}$
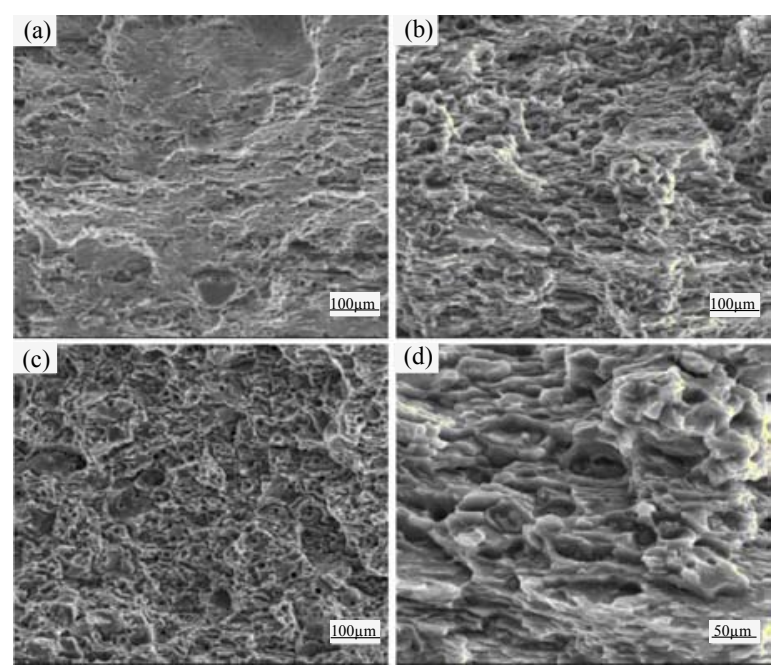

Figure 5: SEM fracture surfaces of aged alloy solution treated at: (a) $510^{\circ} \mathrm{C}$; (b) 520; (c) $525^{\circ} \mathrm{C}$; (d) $520^{\circ} \mathrm{C} / 30 \mathrm{~min}$ 

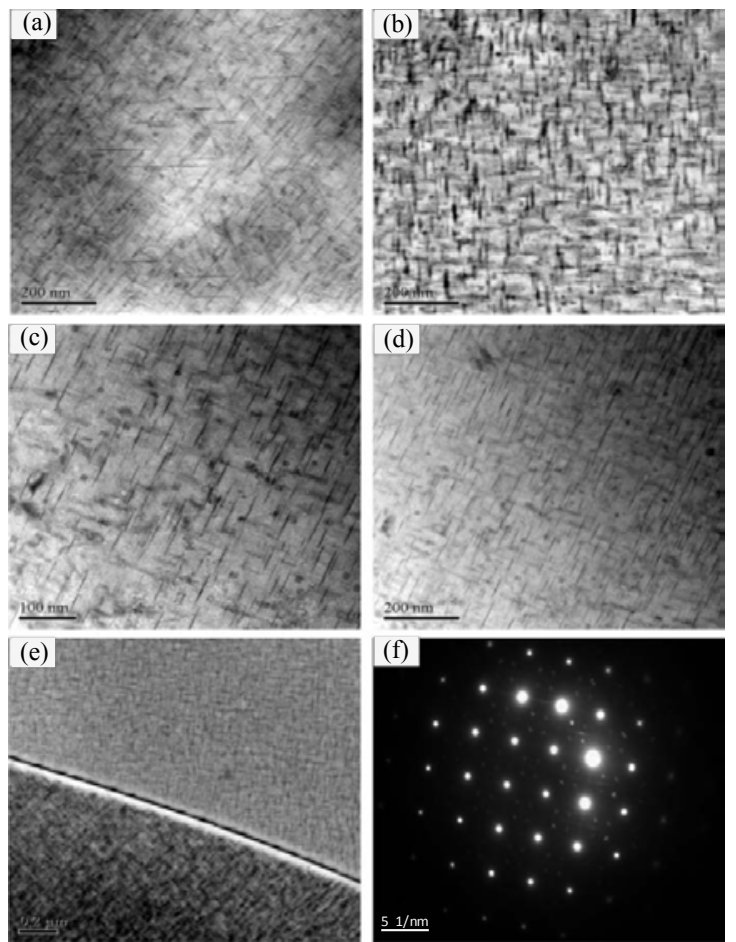

Figure 6: TEM micrographs of aged alloy solution treated at: (a) 510; (b) 520; (c) 525; (d) 520/30min; (e) PFZ at 520/30min; (f) [100] direction.

a well combination of strength, ductility and toughness when solution heat treatment is performed at $520^{\circ} \mathrm{C}$ for $30 \mathrm{~min}$. Therefore, it is very important to treat alloy at proper solution temperature and holding time, which obtain a good combination of mechanical properties.

As is shown in Figure 6, the aged Al-Li-Cu-Mg-Ag alloy solution treated at $520^{\circ} \mathrm{C} / 30 \mathrm{~min}$ precipitates a lot of fine dispersion of uniform distributed $\mathrm{T} 1\left(\mathrm{Al}_{2} \mathrm{CuLi}\right)$ and a few needle-like phases $\theta^{\prime}\left(\mathrm{Al}_{2} \mathrm{Cu}\right)$, which makes the alloy achieve an corresponding optimummicrostructures and mechanical properties. When treated at relative high solution temperature, the vacuum concentration in $\mathrm{Al}$ substrate and the solution atoms, $\mathrm{Cu}$ and $\mathrm{Li}$ Robson et al. [17,18], resulting from redissolution of residual secondary particles both increase, which can increase the matrix supersaturation and the kinectics for precipitation after quenching and is beneficial to the precipitation of T1 and $\theta^{\prime}$ [19]. On the one hand, the secondary phases' transformation dynamic and diffusion of solution atoms are also promoted with the elevated solution temperature. On the other hand, kept for proper solution holding time, the secondary particles can dissolve into $\mathrm{Al}$ matrix perfectly and few bulk phases come to precipitate. However, when the temperature is close to $525^{\circ} \mathrm{C}$, overburning microstructures will appear in the triangle grain boundary connection shown in the Figure $4 \mathrm{~d}$.

\section{Conclusions}

1) The optimum solution treatment of Al-1.3, LI-5.8, Cu-0.4, Mg$0.14, \mathrm{Zr}-0.3$ (wt.\%) alloy is treated at $520^{\circ} \mathrm{C}$ for $30 \mathrm{~min}$.

2)The temperature and time of solution treatment have a significant influence on size of grains, microstructures of alloy, dispersion of the second phases and distortion of crystal lattices, which can be in the present of mechanical properties of alloy.

3) Under the superior solution condition, the alloy achieve excellent microstructures, which a lot of fine dispersion of uniform distributed $\mathrm{T} 1\left(\mathrm{Al}_{2} \mathrm{CuLi}\right)$ and a few needle-like phases $\theta^{\prime}$ can be obtained, and the optimum corresponding mechanical properties: $\sigma \mathrm{b}=566 \mathrm{Mpa}, \sigma 0.2=512 \mathrm{Mpa}, \delta=8.23 \%$ and hardness $=148 \mathrm{HB}$.

\section{Acknowledgements}

The authors would like to thank for the help and discussion of Prof. Zhen and Yin and the support of the Key of national laboratory in Central South University.

\section{References}

1. Yin DF, Zheng ZQ (2003) History and current status of aluminium-lithium alloys. Materials Review 17: 18-20.

2. Huang L, Zheng Z, Li S, Jiang N, Fan Y, et al. (2002) Study and application of aluminium-lithium Alloy. Materials Review.

3. Fan YQ, Chen ZG, Zheng ZQ, Li YF (2005) Effects of multi-stage ageing treatments on microstructure and mechanical properties of Al-Cu-Li-Mg-Mn$\mathrm{Zr}$ alloys. Trans Nonferrous Met Soc China 15

4. Han NM, Zhang XM, Liu SD, He DG, Zhang R (2011) Effect of solution treatment on the strength and fracture toughness of aluminium alloy 7050 . J Alloys Compd 509: 4138-4145.

5. Yuan ZS, Zheng Lu, Xie YH, Dai SL, Liu CH (2007) Effect of plastic deformation on microstructure and properties of high strength $\mathrm{Al}-\mathrm{Cu}-\mathrm{Li}-\mathrm{X}$ aluminium-lithium Alloy. Rare Metal Materials and Engineering 493-496.

6. Shercliff HR, Ashby MF (1990) A process model for age hardening of aluminium alloys-I. The model. Acta Metallurgica et Materialia 38: 1789-1802.

7. Ghosh K S, Das K, Chatterjee UK (2004) Characterization of retrogression and reaging behavior of $8090 \mathrm{Al}-\mathrm{Cu}-\mathrm{Li}-\mathrm{Mg}-\mathrm{Zr}$ alloy. Metallurgical and Materials Transactions A 35: 3681-3691.

8. Song M, He Y, Xiao D, Huang B (2009) Effect of thermomechanical treatment on the mechanical properties of an Al-Cu-Mg alloy. Mater Des 30: 857-861.

9. Senkov ON, Shagiev MR, Senkova SV, Miracle DB (2008) Precipitation of $\mathrm{Al}_{3}(\mathrm{Sc}, \mathrm{Zr}$ ) particles in an $\mathrm{Al}-\mathrm{Zn}-\mathrm{Mg}-\mathrm{Cu}-\mathrm{Sc}-\mathrm{Zr}$ alloy during conventional solution heat treatment and its effect on tensile properties. Acta Mater 56: 3723-3738.

10. Zhu Z, Starink MJ (2008) Solution strengthening and age hardening capability of Al-Mg-Mn alloys with small additions of Cu. Mater Sci Eng : A 488: 125-133.

11. Starink MJ, Hobson AJ, Sinclair I, Gregson PJ (2000) Embrittlement of Al-LiCu-Mg alloys at slightly elevated temperatures: microstructural mechanisms of hardening. Mater Sci Eng A 289: 130-142.

12. Eddahbi M, Jiménez JA, Ruano OA (2007) Microstructure and creep behaviour of an Osprey processed and extruded Al-Cu-Mg-Ti-Ag alloy. J Alloys Comp 433: $97-107$

13. Bakavos D, Prangnell PB, Bes B, Eberl F (2008) The effect of silver on microstructural evolution in two $2 x x x$ series Al-alloys with a high $\mathrm{Cu}: \mathrm{Mg}$ ratio during aging to a T8 temper. Mat Sci Eng 491: 214-223.

14. Xiao DH, Song M (2009) Superplastic deformation of an as-rolled Al-Cu-Mg-Ag alloy. Mater Des 30: 424-426.

15. Zhang DL, Zheng LH, StJohn DH (2002) Effect of a short solution treatment time on microstructure and mechanical properties of modified Al-7 wt. $\% \mathrm{Si}-0.3$ wt.\% Mg alloy. Light Metals 2: 27-36.

16. Li HY, Tang Y, Zeng Z, Zheng Z, Zheng F (2008) Effect of aging time on strength and microstructures of an Al-Cu-Li-Zn-Mg-Mn-Zr alloy. Mater Sci Eng A 498: 314-320.

17. Robson JD (2002) Optimizing the homogenization of Zirconium containing commercial aluminium alloys using a novel process model. Mater Sci Eng: A 338: $219-229$.

18. Wloka J, Hack T, Virtanen S (2007) Influence of temper and surface condition on the exfoliation behaviour of high strength $\mathrm{Al}-\mathrm{Zn}-\mathrm{Mg}-\mathrm{Cu}$ alloys. Corrosion Science 49: 1437-1449.

19. Robinson JS, Tanner DA (2006) The influence of aluminium alloy quench sensitivity on the magnitude of heat treatment induced residual stress. Materials Science Forum 525: 305-310. 